\title{
THE EFFECTS OF CALCIUM AND POTASSIUM DIHYDROGEN PHOSPHATE ON THE PROPERTIES OF MAGNESIUM OXYSULFATE CEMENTS
}

\author{
KEJIA LUO*, "CHENGYOU WU*,**, ZHEN LI*, PANPAN LIU *, RUIYANG PANG*, \\ CONG CHEN*, YUANJI CHEN*, HUIFANG ZHANG******* \\ * School of Civil Engineering, Qinghai University, \\ Xining 810016, PR China \\ **Key Laboratory of Building Energy-saving Materials and Engineering Safety of Qinghai Province, \\ Xining 810016, PR China \\ ***Key Laboratory of Comprehensive and Highly Efficient Utilization of Salt Lake Resources, Qinghai Institute of Salt Lakes, \\ Chinese Academy of Sciences, Xining 810008, PR China. \\ ****Key Laboratory of Salt Lake Resources Chemistry of Qinghai Province, \\ Xining 810008, PR China \\ "E-mail: wuchengyou86@163.com
}

Submitted May 21, 2019; accepted September 16, 2019

\begin{abstract}
Keywords: Magnesium oxysulfate cement, Setting time, Compressive strength, Hydration heat release, Porosity
Magnesium oxysulfate (MOS) cement is a newly-developed material, which shows the advantages of being protected from steel, being light weight, having low alkalinity, being fire-proof, and having a decorative value. Large-scale applications of MOS cement in civil engineering have been restricted by its low strength, which can be improved by adding the proper additives. Here, the effects of dihydrogen phosphate on the setting time, compressive strength, and water resistance of the MOS cement have been studied. The studies on the effects of dihydrogen phosphate on the hydration process of the MOS cement have been studied relative to the hydration-heat release rate. X-ray diffraction, scanning electron microscopy, and mercury intrusion porosimetry were used to examine the hydration products and the pore-size distribution of the MOS cement. The analytical results show that dihydrogen phosphate as an admixture can reduce the direct hydration of $\mathrm{MgO}$ into $\mathrm{Mg}(\mathrm{OH})_{2}$, promote the formation of the $5 \cdot 1 \cdot 7$ strength phase, and improve the strength and water resistance of the cement to some extent. However, dihydrogen phosphate will prolong the setting time of the cement to some extent.
\end{abstract}

\section{INTRODUCTION}

Magnesium oxysulfate (MOS) cement is a gas-hardening magnesium cementitious material formed by an active magnesium oxide and a magnesium sulfate solution [1-3]. Magnesium oxysulfide cement has many advantages in civil engineering, such as being a reinforcement material, having a high strength, having high temperature resistance, having low thermal conductivity, and having good water resistance [4-6]. Compared with MOC (magnesium oxychloride) cement, the prospects of MOS are broader [7]. At present, research on magnesium cement is mainly limited to MOC, and there is little attention paid to MOS cement, mainly because of its low mechanical strength. Therefore, its modification has attracted the attention of many scholars. If the strength properties of MOS cement can be improved, MOC cement will be replaced in some cases, especially under high temperature and water resistance conditions.

At present, the modification technology of the $\mathrm{MgO}-\mathrm{MgSO}_{4}-\mathrm{H}_{2} \mathrm{O}$ ternary gelling system generally improves the strength and volume stability of the sulfateoxygen magnesium cement by adding an admixture to change the composition of the hydrated phase. Demediuk [5] used four forms of $\mathrm{MgO}-\mathrm{MgSO}_{4}-\mathrm{H}_{2} \mathrm{O}$ ternary compounds in a $\mathrm{MgSO}_{4}$ solution from $30{ }^{\circ} \mathrm{C}$ to $120{ }^{\circ} \mathrm{C}$ and studied its properties using X-ray and heat detection methods. The four phases were $5 \mathrm{Mg}(\mathrm{OH})_{2} \cdot \mathrm{MgSO}_{4} \cdot \mathrm{H}_{2} \mathrm{O}(5 \cdot 1 \cdot 3$ phase $)$ or $(5 \cdot 1 \cdot 2$ phase $)$, $3 \mathrm{Mg}(\mathrm{OH})_{2} \cdot \mathrm{MgSO}_{4} \cdot 8 \mathrm{H}_{2} \mathrm{O}(3 \cdot 1 \cdot 8$ phase $), \mathrm{Mg}(\mathrm{OH})_{2} \cdot \mathrm{MgSO}_{4} \cdot$ $\cdot 5 \mathrm{H}_{2} \mathrm{O}(1 \cdot 1 \cdot 5$ phase $)$, and $\mathrm{Mg}(\mathrm{OH})_{2} \cdot 2 \mathrm{MgSO}_{4} \cdot 3 \mathrm{H}_{2} \mathrm{O}(1 \cdot 2 \cdot 3$ phase). Urwong [8] dissolved $\mathrm{MgO}$ in an $\mathrm{H}_{2} \mathrm{SO}_{4}$ solution and indicated by $\mathrm{Mg}$-ray analysis that $\mathrm{Mg}(\mathrm{OH})_{2}$, $3 \mathrm{Mg}(\mathrm{OH})_{2} \cdot \mathrm{MgSO}_{4} \cdot 8 \mathrm{H}_{2} \mathrm{O}(3 \cdot 1 \cdot 8$ phase $), \mathrm{MgSO}_{4} \cdot 7 \mathrm{H}_{2} \mathrm{O}$, $\mathrm{MgSO}_{4} \cdot 6 \mathrm{H}_{2} \mathrm{O}$, and $\mathrm{MgSO}_{4} \cdot \mathrm{H}_{2} \mathrm{O}$ were stable at $23{ }^{\circ} \mathrm{C}$, due to a phase content of less than $50 \%$, which was the main reason for its low strength. Kahle [4] showed that under conditions of steam curing, cement stones with a combination of a $3 \cdot 1 \cdot 8$ phase and a 5.3 .3 phase can be obtained. The German Max Planck Solid State Physics Laboratory [9] analysed the powder diffraction technique of the $3 \cdot 1 \cdot 8$ phase of the $\mathrm{Mg}(\mathrm{OH})_{2}-\mathrm{MgSO}_{4}-$ $\mathrm{H}_{2} \mathrm{O}$ ternary system and proved the existence of the $3 \cdot 1 \cdot 8$ phase by thermodynamic analysis, which was not stable at ambient conditions. Beaudoin [10] studied the porosity of MOS cement and showed that the porosity 
is the main reason for the lower strength of the MOS cement compared to the MOC cement.

Previous studies have shown that the main way to increase the strength of MOS cement is to inhibit the formation of $\mathrm{Mg}(\mathrm{OH})_{2}$ and the addition of modifiers is used to improve the performance. For example, adding phosphoric acid, amino trimethylene phosphonic acid, and citric acid [10-12] can significantly improve the compressive strength and water resistance of the MOS cement by promoting the formation of $5 \mathrm{Mg}(\mathrm{OH})_{2}$ $\mathrm{MgSO}_{4}-7 \mathrm{H}_{2} \mathrm{O}(5 \cdot 1 \cdot 7$ phase). However, as a modifier, these materials have a certain retarding effect on the MOS cement [13]. For example, phosphoric acid $\left(\mathrm{H}_{3} \mathrm{PO}_{4}\right)$ is slightly more effective than phosphate in retarding the solidification $[6,14]$. The addition of the modifier shortens the time interval between the initial and final solidification times of the MOS cement sample. This may be due to the additive changes of the $\mathrm{MgO}$ hydration process and promotes the crystallisation of the new crystalline phase in the MOS cement. Soluble phosphates are commonly used as retarders in Portland cement based on their ability to form complexes with hydrated products in the cement-water systems and affect the hydration reactions [15-17]. Phosphate has also been extensively studied as a barium sulfate inhibitor [18-19]; in these studies, it has been proposed that a phosphate group can replace the sulfate site grown on the twin surface. Also, the addition of a soluble phosphate to the MOS cement has been reported in some patents [20-21].

It is well known that the strength of MOC cement is soluble in water, so the water resistance of MOC cement is poor [19]. Soluble phosphate has been used as a modifier to improve the water resistance of the MOC [5] At the same time, soluble phosphates can also be used as a modifier for MOS cement [10]. However, phosphate is currently soluble as a modifier, while slightly soluble dihydrogen phosphate is rarely reported as a modifier. In this study, we discuss the effects of hydrogen phosphate ions on the MOS, including the setting time, compressive strength, hydration heat release law, and x-ray diffraction (XRD) phase analysis. Scanning electron microscopy
(SEM) was used to analyse the phase characteristics and morphology of the hydration products and discuss the effects of the solubility on the MOS modification.

\section{EXPERIMENTAL}

\section{Raw materials}

- The magnesia used in this study is light-burned magnesia (LBM) obtained by calcining magnesite from Liaoning, China at $750-850{ }^{\circ} \mathrm{C}$, and the chemical composition of the powder is shown in Table 1. The specific surface area of the LBM was determined using the Brunauer-Emmett-Teller (BET) method to be $13.56 \mathrm{~m}^{2} \cdot \mathrm{g}^{-1}$.

Table 1. The chemical composition of the light burned magnesia powder.

\begin{tabular}{lcccccc}
\hline Component & $\mathrm{MgO}$ & $\mathrm{CaO}$ & $\mathrm{SiO}_{2}$ & $\mathrm{Al}_{2} \mathrm{O}_{3}$ & $\mathrm{Fe}_{2} \mathrm{O}_{3}$ & LOI \\
\hline Mass fraction (\%) & 81.21 & 1.33 & 5.67 & 0.18 & 0.52 & 11.09 \\
\hline
\end{tabular}

- The magnesium sulfate $\left(\mathrm{MgSO}_{4} \cdot 7 \mathrm{H}_{2} \mathrm{O}\right.$ crystal) used in this study is analytically pure and was purchased from Tianjin Kemi Europe Chemical Co, Ltd.

- The additives used in this study are soluble calcium dihydrogen phosphate $\left(\mathrm{Ca}\left(\mathrm{H}_{2} \mathrm{PO}_{4}\right)_{2}\right)$ and soluble potassium dihydrogen phosphate $\left(\mathrm{KH}_{2} \mathrm{PO}_{4}\right)$, which are both produced at Tianjin Dingsheng Xin Chemical Co., Ltd.

\section{Specimen preparation}

The mixture's design of the MOS is listed in Table 2 (the ratios of the soluble calcium dihydrogen phosphate $\left(\mathrm{Ca}\left(\mathrm{H}_{2} \mathrm{PO}_{4}\right)_{2}\right)$ and the soluble potassium dihydrogen phosphate $\left(\mathrm{KH}_{2} \mathrm{PO}_{4}\right)$ with the light-burned magnesite (LBM) in Table 2 show their molar ratio, and the values of the letter ' $\mathrm{n}$ ' from $\mathrm{n}(\mathrm{MgO}): \mathrm{n}\left[\left(\mathrm{H}_{2} \mathrm{PO}_{4}\right)^{-}\right]$are 1:0.001, 1:0.0015, and 1:0.002, respectively). According to other

Table 2. The experimental compositions of the MOS.

\begin{tabular}{lcccc}
\hline $\begin{array}{l}\text { Test } \\
\text { number }\end{array}$ & $\begin{array}{c}\text { Molar ratio } \\
\left.(\alpha-\mathrm{MgO} / \mathrm{MgSO})_{4}\right)\end{array}$ & $\begin{array}{c}\text { Molar ratio } \\
(\mathrm{MgO}): n\left[\left(\mathrm{Ca}\left(\mathrm{H}_{2} \mathrm{PO}_{4}\right)_{2}\right)\right.\end{array}$ & $\begin{array}{c}\text { Molar ratio } \\
n(\mathrm{MgO}): n\left(\mathrm{KH}_{2} \mathrm{PO}_{4}\right)\end{array}$ & $\begin{array}{c}\text { Water cement } \\
\text { ratio }(\mathrm{W} / \mathrm{C})\end{array}$ \\
\hline $\mathrm{Ca} 0 \mathrm{~K} 0$ & 7 & 0 & 0 & 0.31 \\
$\mathrm{Ca}$ K0 & 7 & 0.001 & 0 & 0.31 \\
$\mathrm{Ca}$ K0 & 7 & 0.0015 & 0 & 0.31 \\
$\mathrm{Ca3K0}$ & 7 & 0.002 & 0 & 0.31 \\
$\mathrm{Ca}$ KK1 & 7 & 0 & 0.002 & 0.31 \\
$\mathrm{Ca}$ KK2 & 7 & 0 & 0.003 & 0.31 \\
$\mathrm{CaOK} 3$ & 7 & 0 & 0.004 & 0.31 \\
\hline
\end{tabular}

(dihydrogen phosphate, $K$ - potassium dihydrogen phosphate, $S$ - bubble water $60 \mathrm{~d}, 0,1,2$, and 3 indicate the amount of the calcium dihydrogen phosphate or potassium dihydrogen phosphate added. For example, Ca1K0 represents a test group in which the ratio of the molar amount of the calcium dihydrogen phosphate to the molar amount of magnesium oxide is 0.001 , without adding the potassium dihydrogen phosphate, the molar ratio is 7, and the water-cement ratio is 0.31 ; Ca1K0S indicates the test group after soaking in water for 60 days after Ca1K0 was cured for 28 days.) 
research [23], the $\alpha-\mathrm{MgO}$ content of the LBM powder can be determined by a standard hydration method. $\mathrm{MgSO}_{4} \cdot 7 \mathrm{H}_{2} \mathrm{O}$ was first dissolved in deionised water to form a $25.0 \%$ magnesium sulfate solution (the molar ratio of $\mathrm{H}_{2} \mathrm{O} / \mathrm{MgSO}_{4}$ is 20.0). Next, the LBM powder was mixed with the calcium dihydrogen phosphate and potassium dihydrogen phosphate, respectively, according to the ratio in Table 2 . Then the prepared magnesium sulfate solution was added and mechanically stirred to form the MOS cement paste. The MOS cement paste was cast in steel moulds with dimensions of $20 \times$ $20 \times 20 \mathrm{~mm}$, sealed and cured at a temperature of $20^{\circ} \mathrm{C}$ $\pm 2{ }^{\circ} \mathrm{C}$ and a relative humidity of $50 \% \pm 5 \%$ before demoulding. The formula is as follows:

$$
K=\frac{f}{F}
$$

where $K$ is the softening coefficient, $f$ and $F$ are mean strengths after the immersion and the base sample strength after 28 days curing, respectively.

\section{Specimen analysis}

The initial setting time and final setting time of the MOS were determined using a Vicar apparatus according to the testing standard GB / T 1346-2011 (《 Test methods for water requirement for normal consistency, setting time and soundness of the Portland cement $\rangle)$ ). The compressive strength was determined according to the testing standard GB175-2007 (《COCommon Portland Cement $\rangle\rangle)$. The hydration-heat release rate of the MOS with the different concentrations of LBM powder was tested using an I-Cal 4000HPC multichannel isothermal calorimeter according to the direct method in the standard of GB/T 12959-2008 (《Test methods for heat of hydration of cement $\rangle\rangle)$. In addition, after testing the strength, the crushed cement was ground to a powder (D90 $<35 \mu \mathrm{m})$ to test its crystal phase composition using an x-ray diffractometer (X-pert Pro) with an acceleration voltage of $30 \mathrm{kV}$ and a scan area of $2 \theta$ with

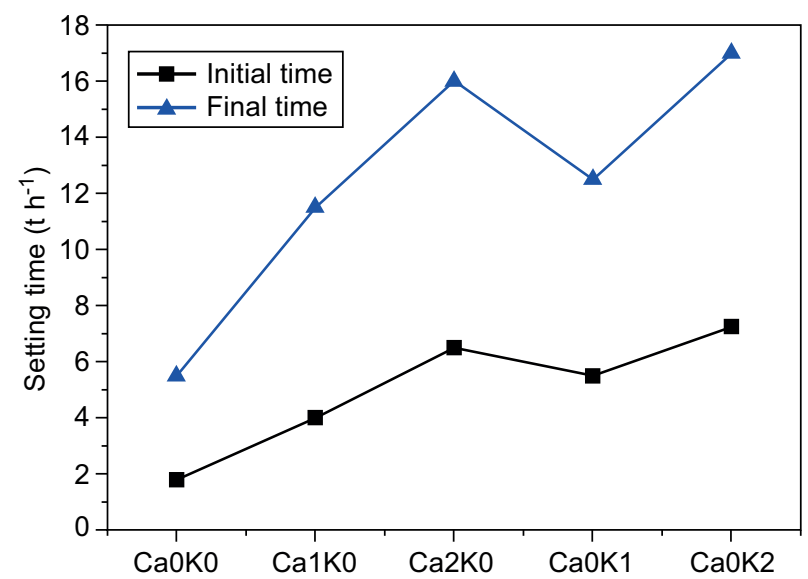

Figure 1. The setting time of the MOS with the different mixtures. a range of $5-70^{\circ}$. Simultaneously, the microstructure and morphology of the MOS samples were observed by scanning electron microscopy (SEM, JSM-6300). Ultimately, the porosity and pore distribution of the MOS samples after 28-days of curing was measured by the mercury intrusion method (Auto Pore 9500).

\section{RESULTS AND DISCUSSION}

\section{Setting time and compressive strength}

The mechanical properties of cement are of great significance in the application of practical engineering. Relevant scholars have pointed out that for sulfur magnesia cement, the most important factor determining its strength is the content of the hydration product $5 \mathrm{Mg}(\mathrm{OH})_{2} \cdot \mathrm{MgSO}_{4} \cdot 7 \mathrm{H}_{2} \mathrm{O}(5 \cdot 1 \cdot 7$ phase) [23]. Figure 1 shows the setting time of the magnesium oxysulfide cement under different mixing ratios. Figure 2 shows the compressive strength of the MOS under different ratios and curing ages. Figures 3 and 4 show the $1 \mathrm{~d}$ XRD pattern and $28 \mathrm{~d}$ XRD pattern of the MOS with different mixtures, respectively.

Dihydrogen phosphate is used as an admixture for the purpose of inhibiting the formation of $\mathrm{Mg}(\mathrm{OH})_{2}$ by adsorption or complexation with the active magnesium oxide hydration layer and promoting $5 \mathrm{Mg}(\mathrm{OH})_{2} \cdot \mathrm{MgSO}_{4}$. $\cdot 7 \mathrm{H}_{2} \mathrm{O}(5 \cdot 1 \cdot 7$ phase) to improve the compressive strength of the MOS cement. However, it can be seen from the condensation time of Figure 1 that the initial setting time and the final setting time of $\mathrm{Ca} 0 \mathrm{~K} 0$ are $1.8 \mathrm{~h}$ and $5 \mathrm{~h}$, and the initial setting time and final setting time of $\mathrm{Ca} 2 \mathrm{~K} 0$ are $6.5 \mathrm{~h}$ and $16 \mathrm{~h}$. Compared with $\mathrm{Ca} 0 \mathrm{~K} 0$, the initial setting time and final setting time of $\mathrm{Ca} 2 \mathrm{~K} 0$ were extended by $4.7 \mathrm{~h}$ and $10.5 \mathrm{~h}$, and the initial setting time and final setting time of $\mathrm{Ca} 0 \mathrm{~K} 2$ were extended by $7.25 \mathrm{~h}$ and $17 \mathrm{~h}$. Compared with $\mathrm{Ca} 0 \mathrm{~K} 0$, the initial setting time and final setting time of $\mathrm{Ca} 2 \mathrm{~K} 0$ were extended by $5.45 \mathrm{~h}$ and $12 \mathrm{~h}$. Therefore, whether it is calcium dihydrogen phosphate or potassium dihydrogen phosphate, both the initial setting time and the final setting time increase with the addition of the admixture, and the larger the dosage, the greater the increase is in the setting time.

It can be seen from Figure $2 \mathrm{a}, \mathrm{b}$ that the control group $\mathrm{Ca} 0 \mathrm{~K} 0$ has a lower compressive strength at the different ages compared with the other experimental groups. Moreover, as the curing age increases, the difference in the compressive strength increases. For example, when $\mathrm{Ca} 0 \mathrm{~K} 0$ is compared with $\mathrm{Ca} 2 \mathrm{~K} 0$, the compressive strength of $\mathrm{Ca} 0 \mathrm{~K} 0$ is $11.2 \mathrm{MPa}$ at $1 \mathrm{~d}$, and the compressive strength of $\mathrm{Ca} 2 \mathrm{~K} 0$ is $15.5 \mathrm{MPa}$. After 1 day, the compressive strength of $\mathrm{Ca} 0 \mathrm{~K} 0$ in the experimental group is $38.4 \%$ higher than that in the control group. At $28 \mathrm{~d}$, the compressive strength of $\mathrm{Ca} 0 \mathrm{~K} 0$ was only $35.8 \mathrm{MPa}$, and the compressive strength of $\mathrm{Ca} 2 \mathrm{~K} 0$ reached $83.5 \mathrm{MPa}$. The compressive strength of $\mathrm{Ca} 2 \mathrm{~K} 0$ in the experimental group was increased by 
$133.34 \%$ compared with the control group Ca0K0 at 28 days. Similarly, potassium dihydrogen phosphate can also have a good modification effect on the compressive strength of the MOS cement. The compressive strength of $\mathrm{Ca} 0 \mathrm{~K} 1$ at $1 \mathrm{~d}$ and $28 \mathrm{~d}$ were $17.2 \mathrm{MPa}$ and $15.5 \mathrm{MPa}$, respectively. Compared with the control group $\mathrm{CaOK} 0$, the strength after $1 \mathrm{~d}$ increased by $53.6 \%$, and the strength after $28 \mathrm{~d}$ increased by $121.2 \%$. In the above compressive strength test, when the calcium dihydrogen phosphate was used as the modifier, the experimental group of $\mathrm{Ca} 2 \mathrm{~K} 0$ had the highest compressive strength at the later stage. When potassium dihydrogen phosphate was used as a modifier, the experimental group $\mathrm{Ca} 0 \mathrm{~K} 1$ had the highest compressive strength at the later stage. Calcium dihydrogen phosphate is difficult to dissolve in a magnesium sulfate solution, but potassium dihydrogen

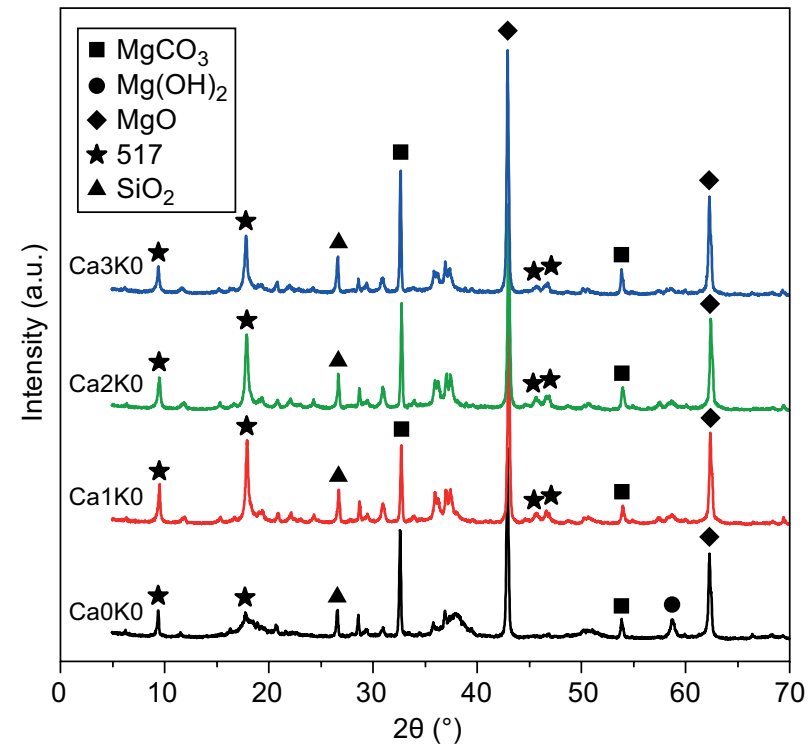

a)

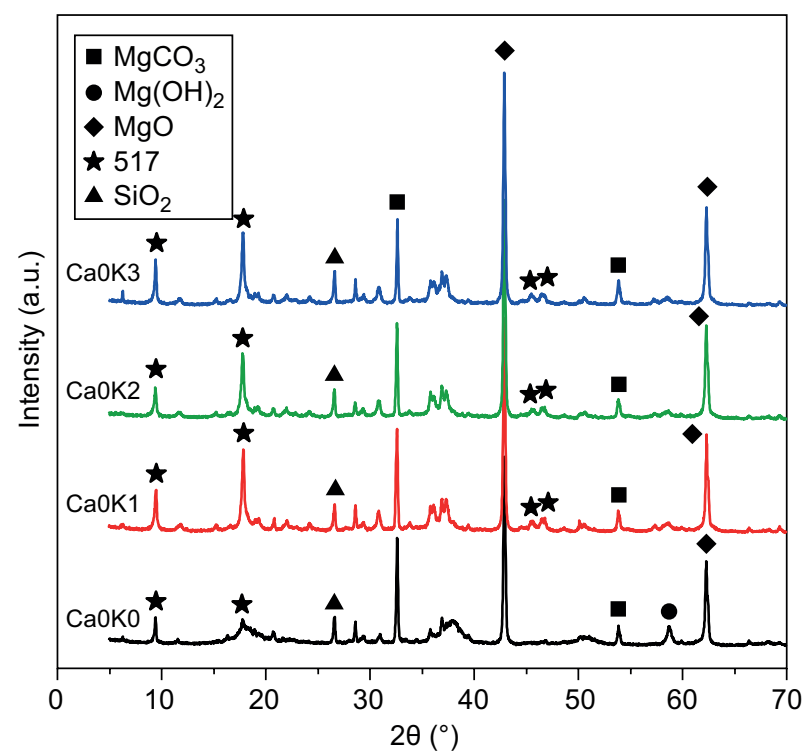

b)

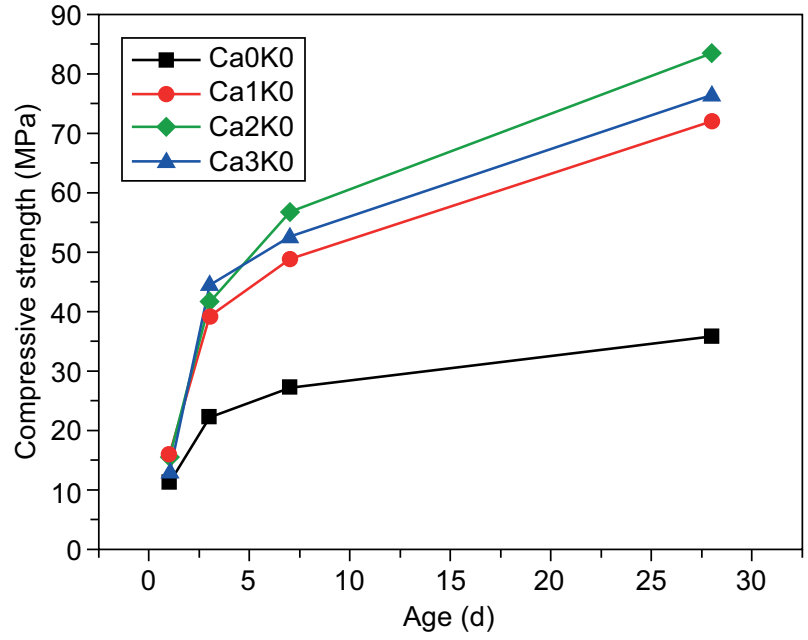

a)

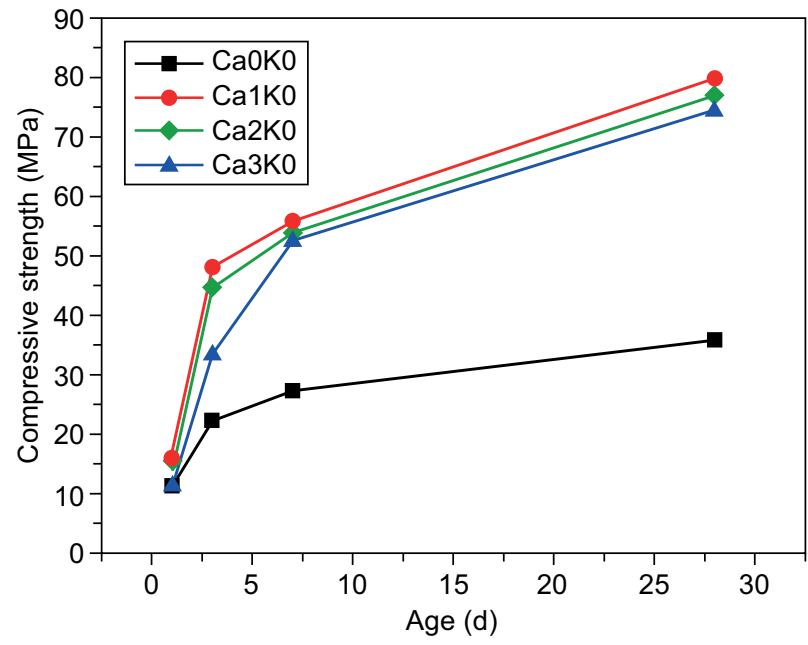

b)

Figure 2. The compressive strength of the MOS with the different mixtures after the different curing times.

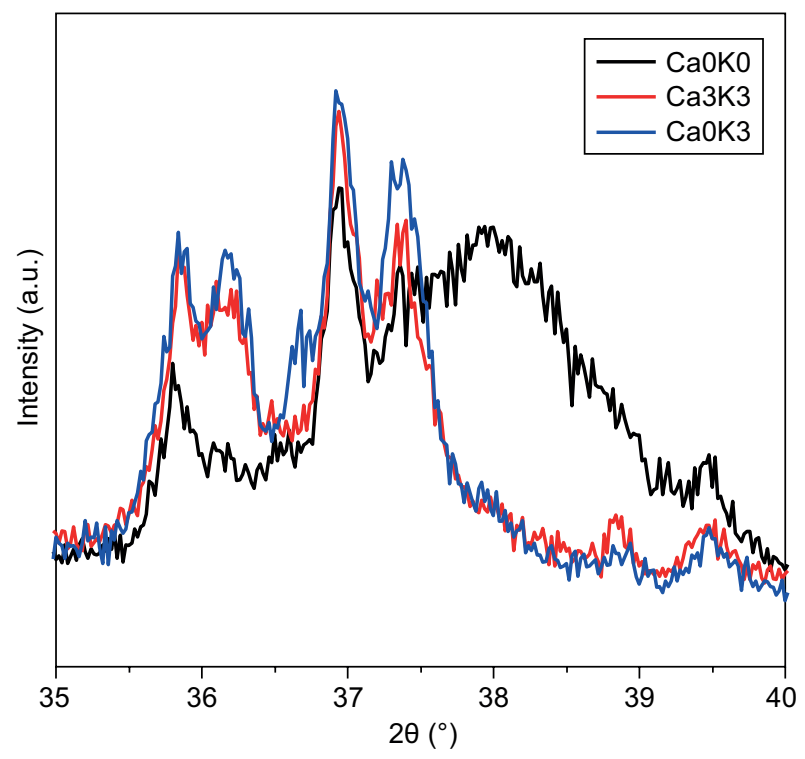

c)

Figure 3. The XRD patterns of the MOS with the different mixtures after curing one day. 
phosphate is easy to dissolve in a magnesium sulfate solution, which may be the requirement of the MOS cement modifiers for the hydrogen phosphate ion concentration.

At the same time, comparing the compressive strength after $1 \mathrm{~d}$, of $\mathrm{Ca} 01 \mathrm{~K} 0$ and $\mathrm{Ca} 3 \mathrm{~K} 0$, it can be found that as the amount of dihydrogen phosphate increased, the compressive strength reduced. For example, at $1 \mathrm{~d}$, the compressive strengths of $\mathrm{Ca} 1 \mathrm{~K} 0$ and $\mathrm{Ca} 0 \mathrm{~K} 1$ are $16 \mathrm{MPa}$ and $17.2 \mathrm{MPa}$, respectively, while the compressive strengths of $\mathrm{Ca} 3 \mathrm{~K} 0$ and $\mathrm{Ca} 0 \mathrm{~K} 3$ are only

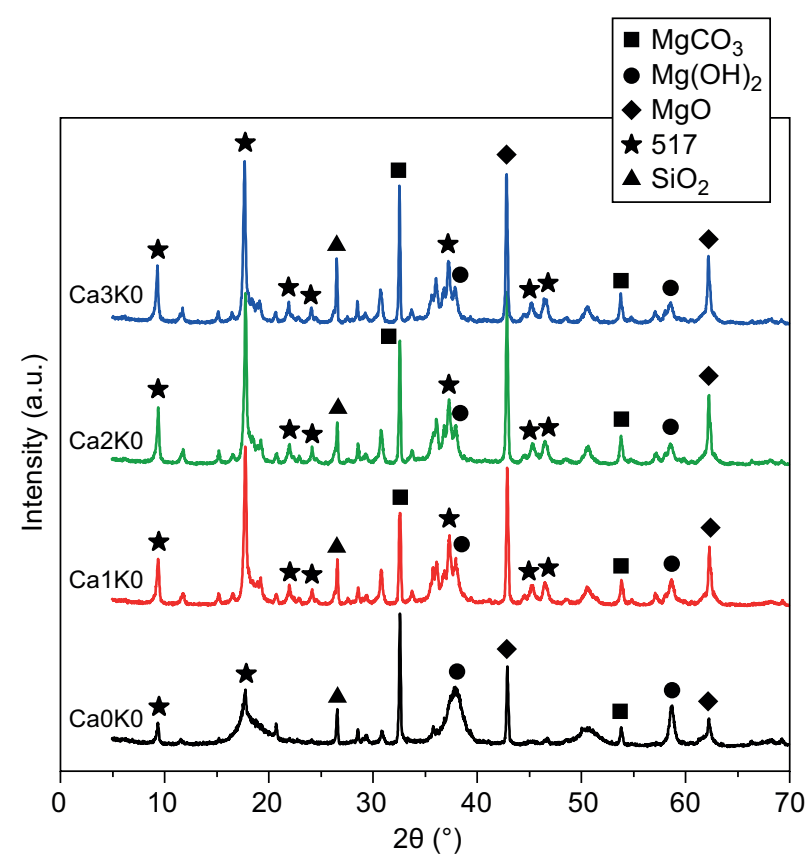

a)

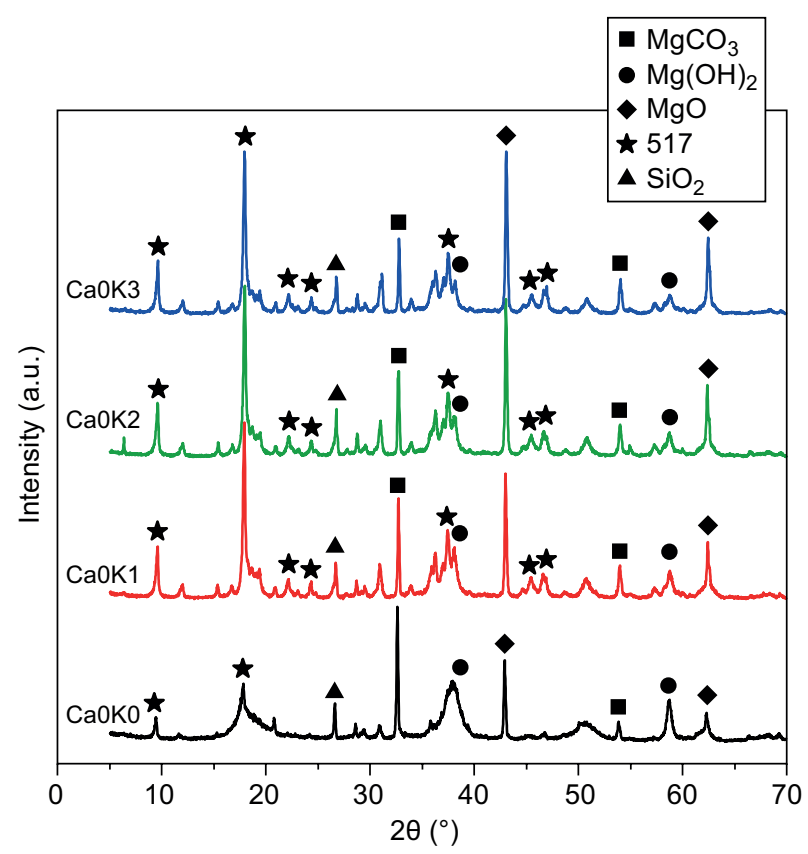

b)
12.8 $\mathrm{MPa}$ and 11.2 $\mathrm{MPa}$. The previously discussed setting time indicates that dihydrogen phosphate affects the setting time of the MOS, and for initial strength, the increase of the dihydrogen phosphate content delays the early hydration of the MOS, resulting in a lower initial strength.

Previous research has shown [23] that tartaric acid can be used as a modifier for MOS cement to promote the 5.1 .7 generation. In Figure $3 a, b$ and Figure $4 a, b$, it can be clearly seen that the peak height of the $5 \cdot 1 \cdot 7$ phase diffraction passes through the XRD pattern, no matter whether it is calcium dihydrogen phosphate or potassium dihydrogen phosphate. This can promote the growth of the the $5 \cdot 1 \cdot 7$ phase, and the strength of the MOS cement is mainly derived from the formation of the $5 \cdot 1 \cdot 7$ phase. According to Figure $3 \mathrm{a}, \mathrm{b}$ and Figure $4 a, b$, it can also be seen that with the incorporation of dihydrogen phosphate, both dihydrogen phosphates can promote the $5 \cdot 1 \cdot 7$ phase of the MOS cement to some extent. It is not directly related to the solubility of the two in the magnesium sulfate solution, so both dihydrogen phosphates can be used as modifiers for the MOS cement. At the same time, in observing the $\mathrm{Mg}(\mathrm{OH})_{2}$ diffraction peak at $38^{\circ}$, it is easy to see that in the control group of $\mathrm{Ca} 0 \mathrm{~K} 0$, the peak is more obvious than other peaks, especially at $1 \mathrm{~d}$, because there is no dihydrogen phosphate in $\mathrm{CaOK} 0$. This leads to the direct hydration of $\mathrm{MgO}$ to $\mathrm{Mg}(\mathrm{OH})_{2}$. However, in the other experimental groups, the dihydrogen phosphate ion complexes with the magnesium hydroxide ion of the magnesium oxide [23], resulting in a decrease in the amount of $\operatorname{Mg}(\mathrm{OH})_{2}$, which promotes the formation of the $5 \cdot 1 \cdot 7$ phase compound and improves the MOS. The compressive strength is also the root cause of the high strength of the experimental group.

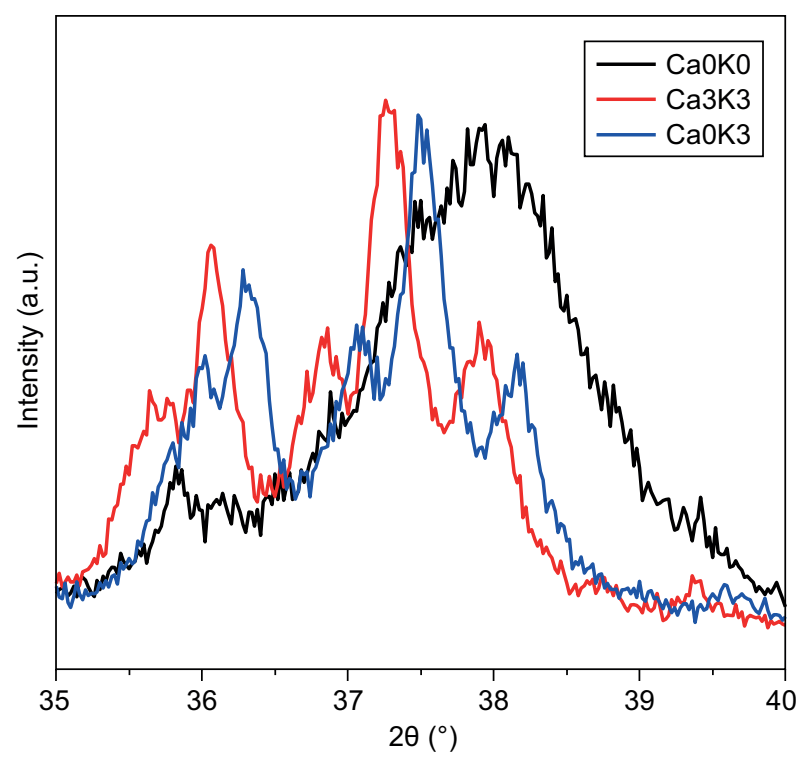

c)

Figure 4. The XRD patterns of the MOS with the different mixtures after curing 28 days. 
Luo K., Wu Ch., Li Z., Liu P., Pang R., Chen C., Chen Y., Zhang H.

In the analysis by the scanning electron microscopy, we cannot observe the topography of the $5 \cdot 1 \cdot 7 \cdot$ phase product due to excess material on the substrate. For the convenience of observation and analysis, we analysed it on the solid-liquid interface of the cement. It can be seen from Figure $5 \mathrm{a}, \mathrm{b}$ that in the control group of $\mathrm{CaOK} 0$, we can only see the sparsely scattered needle-like products, and we can also see the $\mathrm{Mg}(\mathrm{OH})_{2}$ produced by the reaction of $\mathrm{MgO}$ with water. Comparing to Figure $5 \mathrm{c}, \mathrm{d}$, it can be seen that in the case where dihydrogen phosphate is used as a modifier, the effect of promoting the formation of the $5 \cdot 1 \cdot 7$ phase is very remarkable. The shape of the $5 \cdot 1 \cdot 7$ phase is coniferous and intertwined to provide the main strength for the cement.

$$
\mathrm{MgO}(\mathrm{s})+\mathrm{H}_{2} \mathrm{O} \rightarrow \mathrm{Mg}(\mathrm{OH}) \mathrm{Mg}(\mathrm{OH})^{+}{ }_{\text {(surface) }}+\mathrm{OH}^{-}
$$

In the analysis by the scanning electron microscopy, we could not specifically observe the morphology of the $5 \cdot 1 \cdot 7$. phase product due to the excess material on the substrate. To facilitate the observation, the analysis was carried out on the solid-liquid bonding surface of the cement. As can be seen from Figure $4 \mathrm{a}$, in the control group of $\mathrm{Ca} 0 \mathrm{~K} 0$, we can only see the sparsely-scattered whisker-like products, and we can also see the $\mathrm{Mg}(\mathrm{OH})_{2}$ produced by the reaction of $\mathrm{MgO}$ with water. As can be seen with the comparison of Figure 5b,c, in the case where the dihydrogen phosphate is used as a modifier, the effect of promoting the formation of the $5 \cdot 1 \cdot 7$ phase is significant. The shape of the $5 \cdot 1.7$ is coniferous and intertwined to provide the main strength for the cement.

The hydration process can be divided into five stages, namely the pre-induction period, the induction period, the acceleration period, the deceleration period, and the stable period [24]. In the heat release rate map (Figure 6a, c), it can be seen that as the amount of dihydrogen phosphate increases, it will lead to a prolonged induction period, which corresponds to the previous setting time. The increase in the dihydrogen phosphate content will delay the MOS cement acceleration period. For example, for Figure $6 \mathrm{~b}, \mathrm{~d}, \mathrm{Ca} 0 \mathrm{~K} 0$ enters the acceleration period at $3.16 \mathrm{~h}, \mathrm{Ca} / \mathrm{K} 0$ and $\mathrm{Ca} 2 \mathrm{~K} 0$ enter the acceleration period at $7.67 \mathrm{~h}$ and $11.14 \mathrm{~h}$, respectively, while $\mathrm{Ca} 0 \mathrm{~K} 1$ and $\mathrm{Ca} 0 \mathrm{~K} 2$ enter the acceleration period at $8.15 \mathrm{~h}$ and $12.22 \mathrm{~h}$, respectively. This indicates that the dihydrogen phosphate salt also has a retarding effect as a modifier, and as the amount

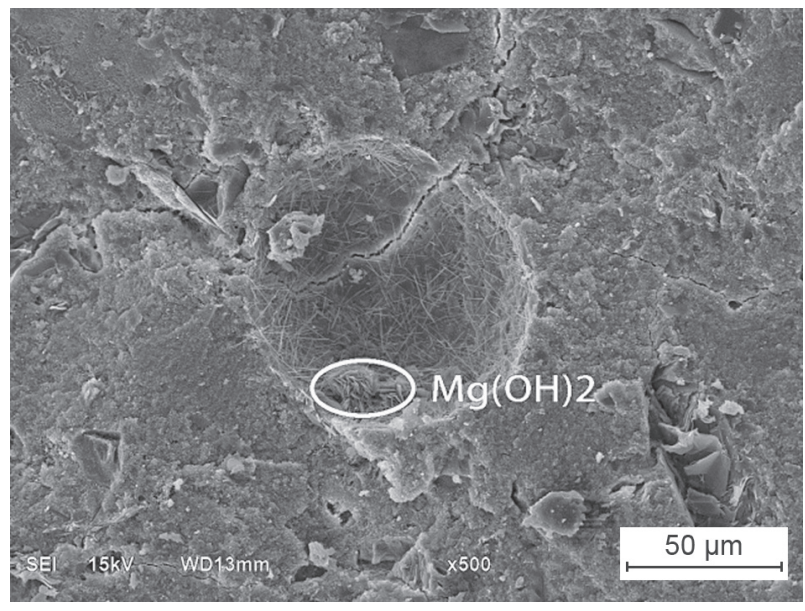

a) $\mathrm{Ca} 0 \mathrm{~K} 0$

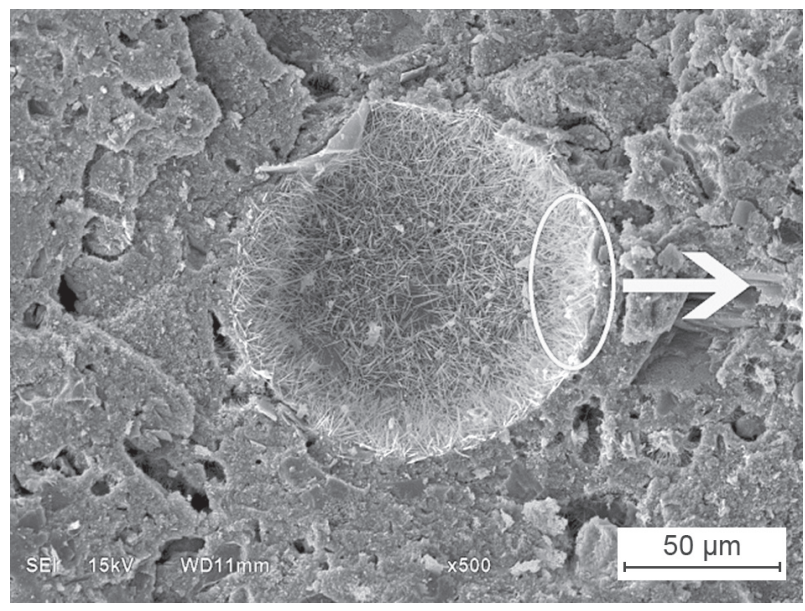

c) $\mathrm{Ca} 2 \mathrm{~K} 0$

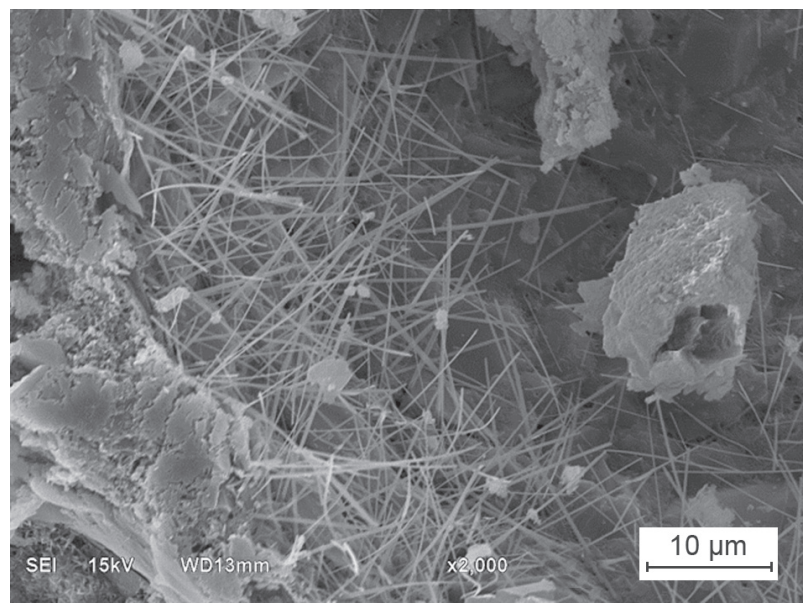

b) $\mathrm{Ca} 0 \mathrm{~K} 0$

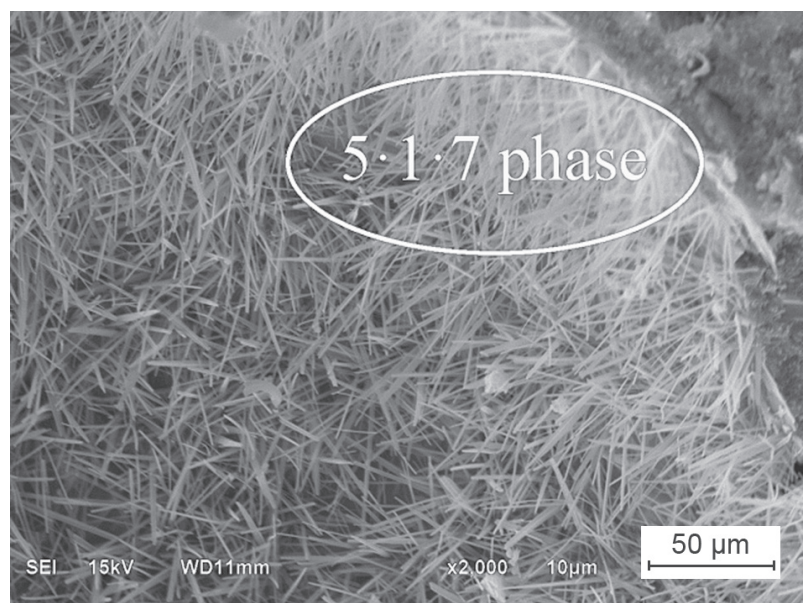

d) $\mathrm{Ca} 2 \mathrm{~K} 0$

Figure 5. The SEM images of the MOS cement for $\mathrm{Ca} 0 \mathrm{~K} 0(\mathrm{a}, \mathrm{b})$ and $\mathrm{Ca} 2 \mathrm{~K} 0(\mathrm{c}, \mathrm{d})$ cured for 28 days. 


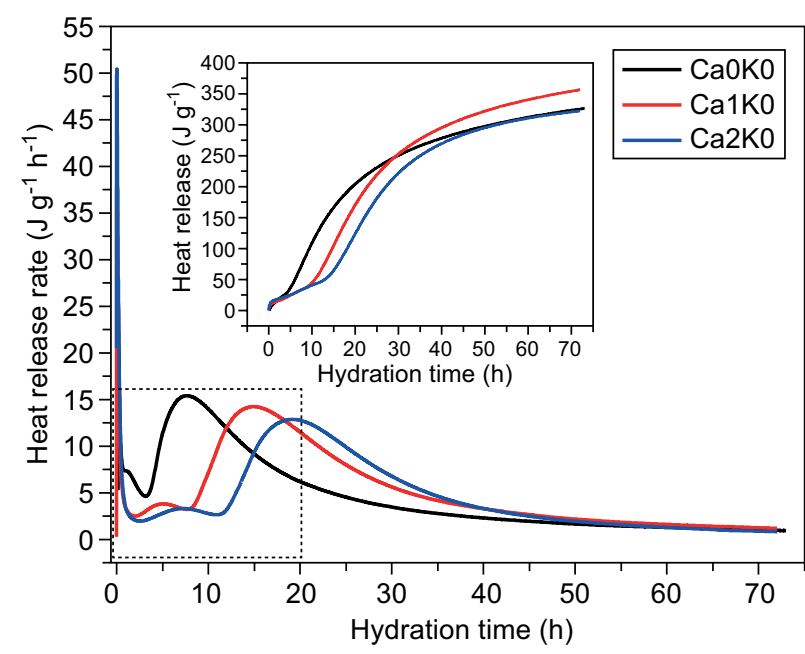

a)

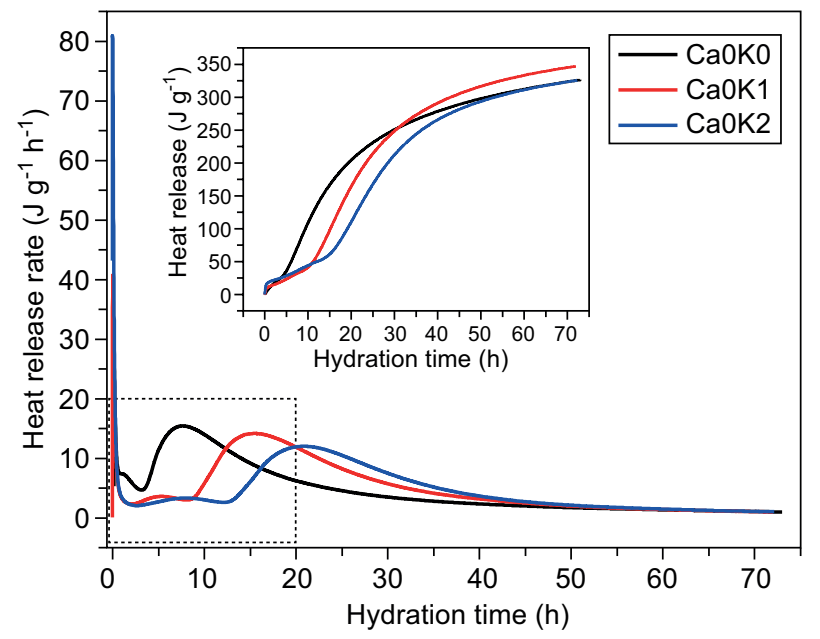

c)

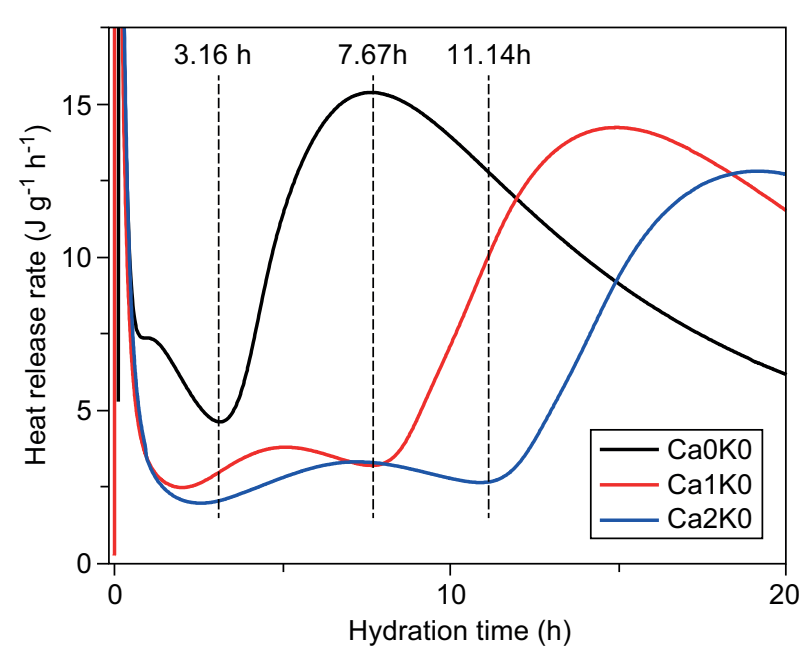

b)

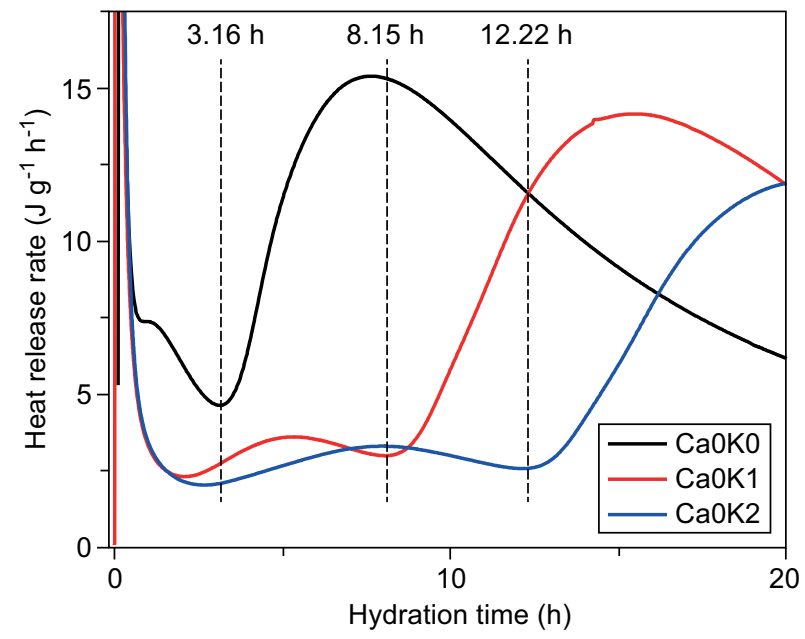

d)

Figure 6. The hydration-heat release rate of the MOS with the different mixtures.

of dihydrogen phosphate increases, the acceleration period of the MOS cement is also delayed. This explains why the high content of dihydrogen phosphate is lower than the strength of the low-yield dihydrogen phosphate (at 1 d). Observing Figure 6a, c, it can be seen that the highest exotherm per unit time will decrease with the increase in the dihydrogen phosphate content, which is of great significance for the prevention of cracking of the concrete mass.

\section{Water resistance}

Figure 7 shows the MOS cement after being cured for 28 days and then soaked in water to test its compressive strength and softening coefficient. After soaking in water, the strength and softening coefficient decreased, and $\mathrm{Ca} 0 \mathrm{~K} 0$ showed severe cracking after 60 days of soaking. When adding dihydrogen phosphate as a modifier, the other experimental groups still have a higher compressive strength after $60 \mathrm{~d}$ of water immersion. It can be seen from Figure $7 \mathrm{~b}$ that the softening coefficients of these experimental groups are greatly improved.

Figure 9 shows the SEM image after soaking for 60 days. It can be clearly seen from Figure 9a, b that the needle-like substance in the hole has changed significantly compared with the 28-day cured sample, and the whisker of the $5 \cdot 1.7$ phase in the hole became short, which may be due to the slight dissolution of the $5 \cdot 1 \cdot 7$ phase in water. At the same time, as shown in Figure 9c, d, compared with the SEM at $28 \mathrm{~d}$, there is no obvious change, because the $5 \cdot 1 \cdot 7$. phase may have a slight amount of dissolution in the water, but the picture and XRD pattern cannot be observed in detail. This is likely because the $5 \cdot 1 \cdot 7$ phase is dissolved and accompanied by a new $5 \cdot 1 \cdot 7$. phase. Figures 8 and 9 show that the strength phase of the $5 \cdot 1 \cdot 7$ phase is still stable in water. However, due to the interaction between the tensile stress and the compressive stress of the test piece during the water soaking, the compressive strength after soaking is still lower than the compressive strength before soaking. 


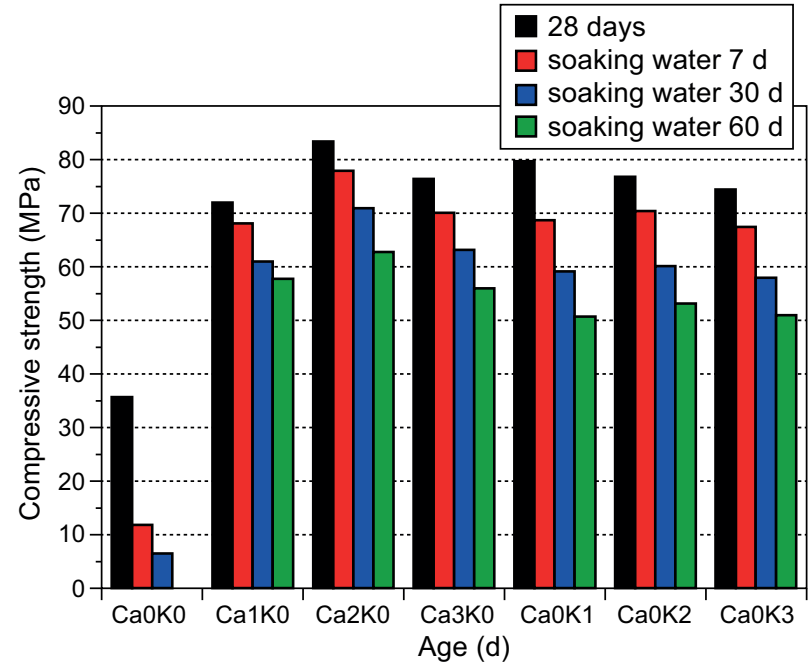

a)

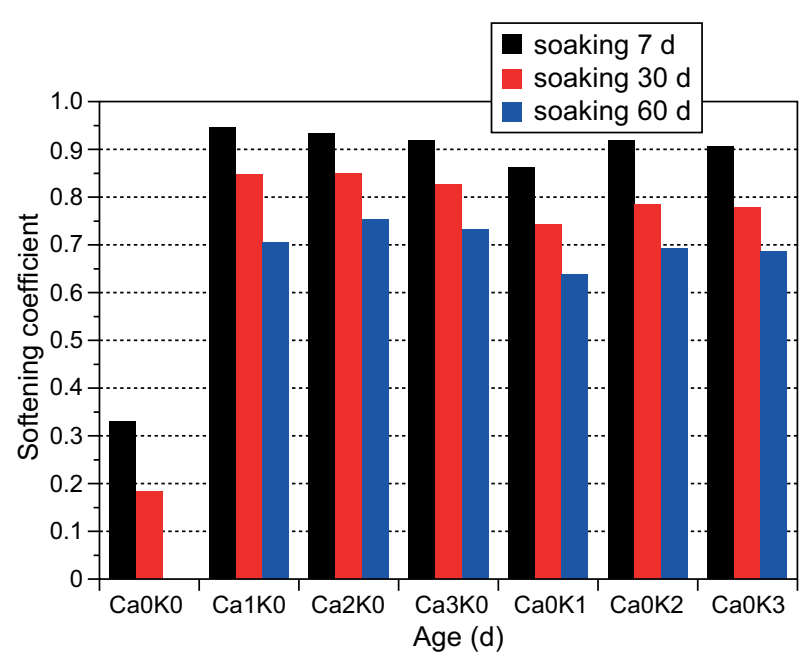

b)

Figure 7. The compressive strength and softening coefficient of the MOS with the different mixtures after water soaking.

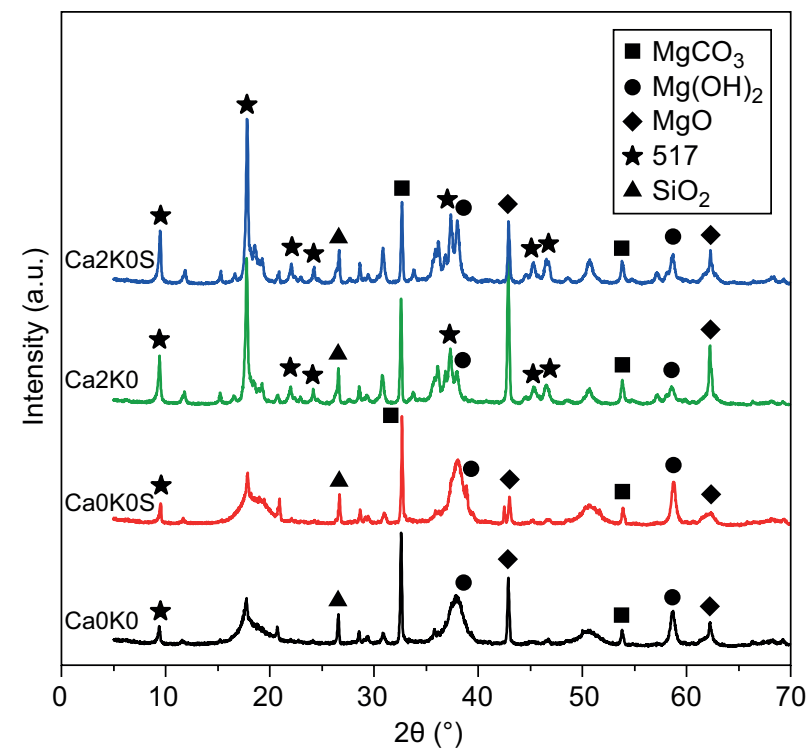

a)

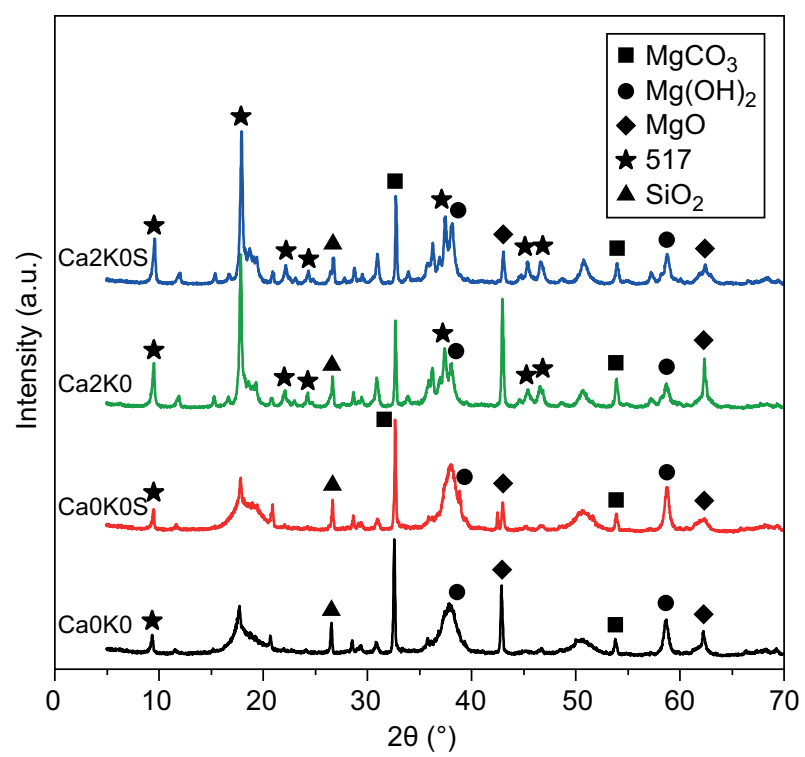

b)

Figure 8. The XRD patterns of the MOS with the different mixtures after 30-days water soaking.

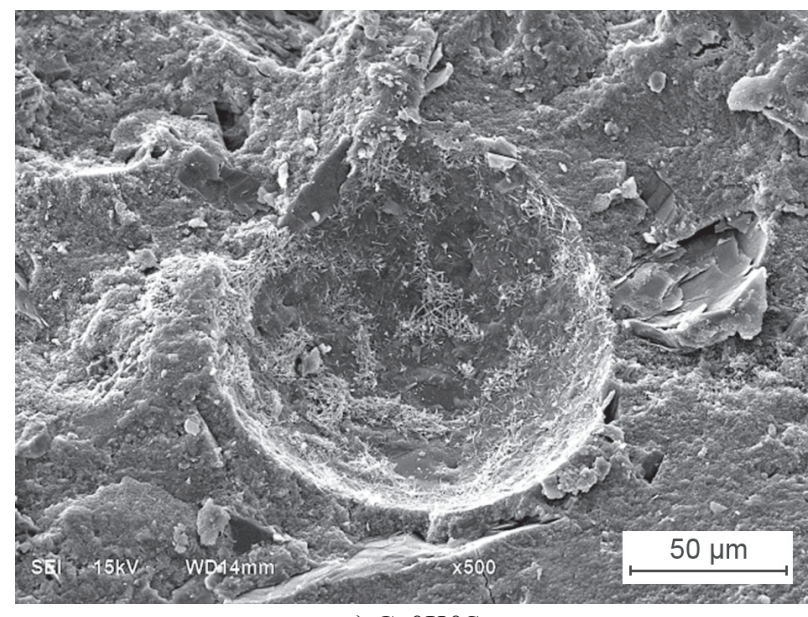

a) $\mathrm{Ca} 0 \mathrm{~K} 0 \mathrm{~S}$

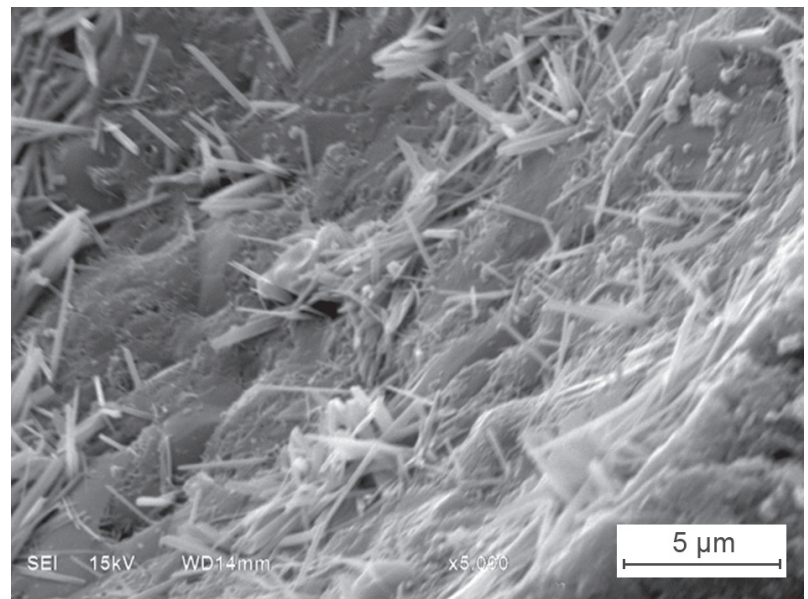

b) $\mathrm{Ca} 0 \mathrm{~K} 0 \mathrm{~S}$

Figure 9. The SEM images of the MOS cement Ca0K0S (a,b) and Ca2K0S (c, d) cured after 28 days. (Continue on next page) 


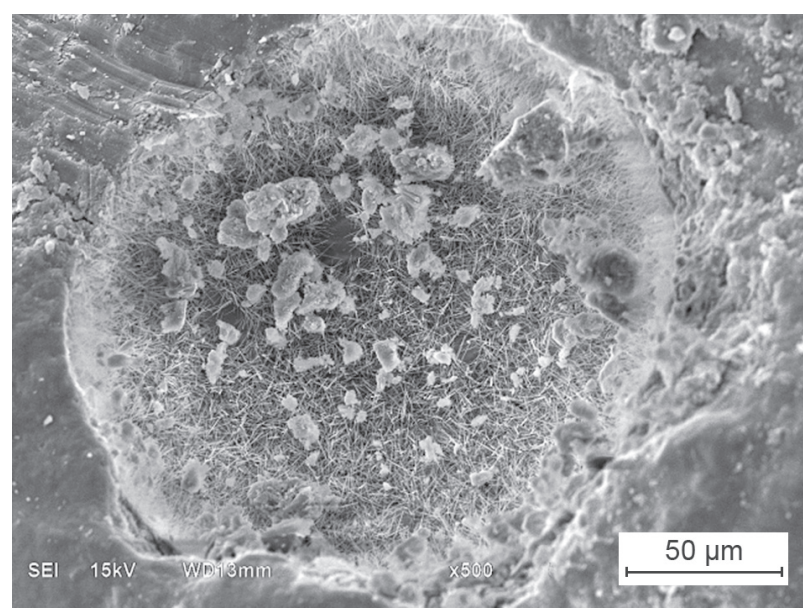

c) $\mathrm{Ca} 2 \mathrm{~K} 0 \mathrm{~S}$

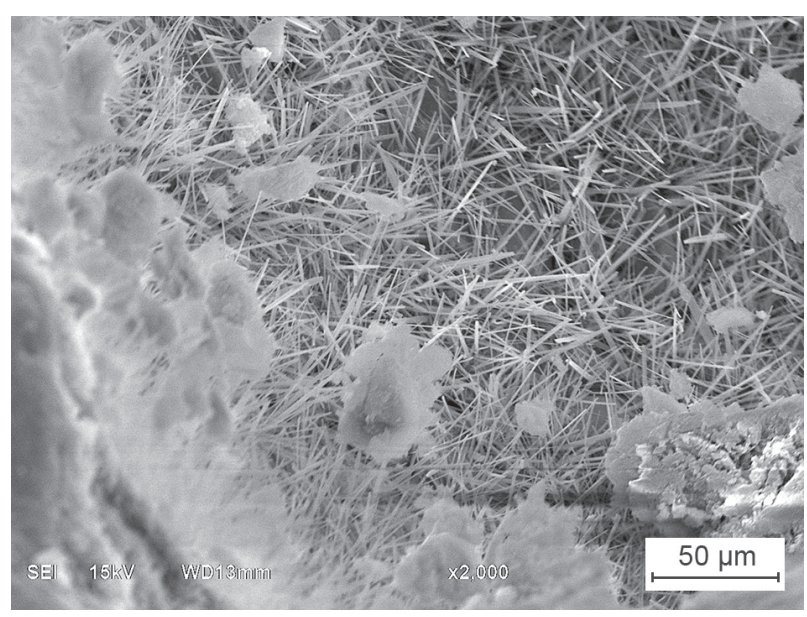

d) $\mathrm{Ca} 2 \mathrm{~K} 0 \mathrm{~S}$

Figure 9. The SEM images of the MOS cement CaOK0S (a,b) and Ca2K0S (c, d) cured after 28 days.

Porosity

The compressive strength of the MOS is closely related to the type and content of the hydration products and their porosity and pore distribution. It can be seen from Figure 12 and Table 3 that the pore size distribution of the control group $\mathrm{Ca} 0 \mathrm{~K} 0$ is significantly different from that of the experimental group, $\mathrm{Ca} 2 \mathrm{~K} 0$ and $\mathrm{Ca} 0 \mathrm{~K} 2$, and the small pores $(\mathrm{D} \leq 10 \mathrm{~nm}$ ) account for a larger proportion. The reason is that the main hydration product of the MOS is the $\mathrm{MgO}-\mathrm{MgSO}_{4}-\mathrm{H}_{2} \mathrm{O}$ ternary gel due to the absence of the incorporation of the dihydrogen phosphate. However, in the experimental group with dihydrogen phosphate as a modifier, the hydration product of MOS was mainly the $5 \cdot 1 \cdot 7$ phase, but the gel cannot be detected by XRD. The pore structure of the gel is denser than the intercrystalline pores of the $5 \cdot 1 \cdot 7$ hydration phase, so the average pore size of $\mathrm{Ca} 0 \mathrm{~K} 0$ is smaller than that of $\mathrm{Ca} 2 \mathrm{~K} 0$ and $\mathrm{Ca} 0 \mathrm{~K} 2$.

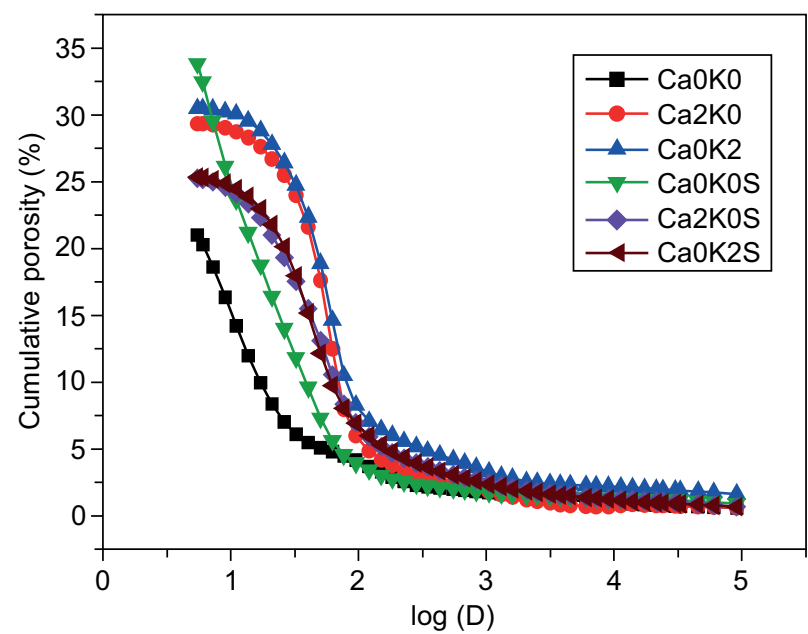

Figure 10. The cumulative porosity of the MOS $-\mathrm{D}$ is the pore diameter (nm).
Comparing $\mathrm{CaOKOS}$ and $\mathrm{CaOK0}$, the average pore size and mesopores $(10 \mathrm{~nm}<\mathrm{D}<100 \mathrm{~nm})$ of the sample after soaking in water will increase, but the ratio of the macropores $(\mathrm{D} \geq 100 \mathrm{~nm}$ ) to the small pores $(\mathrm{D}<10 \mathrm{~nm}$ ) will decrease. This is because the $\mathrm{Ca} 0 \mathrm{~K} 0$ specimen itself has a large amount of $\left(\mathrm{MgSO}_{4} \cdot \mathrm{nH}_{2} \mathrm{O}\right)$ crystallised hydration product, and the gel crystallinity is poor. Therefore, the $\left(\mathrm{MgSO}_{4} \cdot \mathrm{nH}_{2} \mathrm{O}\right)$ crystal hydration product is partially dissolved in the water, resulting in a decrease in the ratio of the small pores and an increase in the ratio of the mesopores. From the previous XRD pattern, we can see that there is still excess $\mathrm{MgO}$ in the sample and will continue to hydrate to form $\mathrm{Mg}(\mathrm{OH})_{2}$ after soaking in the water. However, the formation of $\mathrm{Mg}(\mathrm{OH})_{2}$ causes the test piece to swell, filling a portion of the macropores, but this is not enough to fill the pores left by the dissolution of the magnesium crystallisation hydrate. This leads to an increase in the average pore size and a large ratio of the holes is reduced. Therefore, the $\left(\mathrm{MgSO}_{4} \cdot \mathrm{nH}_{2} \mathrm{O}\right)$ crystal hydration product is partially dissolved in the water, resulting in a decrease in the ratio of the pores (D) and an increase in the ratio of the mesopores. At the same time, it was observed that the water-soaked sample after natural drying shows a surface layer of white powder. This phenomenon may be caused by the substance in the sample being dissolved in the water and being precipitated on the surface of the sample.

In comparison with $\mathrm{Ca} 2 \mathrm{~K} 0 \mathrm{~S}$ and $\mathrm{Ca} 0 \mathrm{~K} 2 \mathrm{~S}, \mathrm{Ca} 2 \mathrm{~K} 0$ and $\mathrm{Ca} 0 \mathrm{~K} 2$ show a reduction in the pore size, but the pore size $(\mathrm{D} \geq 10 \mathrm{~nm}$ ) increases. This phenomenon may be due to two reasons: First, we can see the changes in the content of each substance by the XRD patterns before and after soaking in the water. This is mostly due to the molar ratio of the MOS cement sample of 7 , and the sample itself will have an excessive amount of $\mathrm{MgO}$. Excess magnesium oxide will continue to hydrate and magnesium hydroxide and the $5 \cdot 1 \cdot 7$ phase will form, which will fill the pore structure, resulting 
Luo K., Wu Ch., Li Z., Liu P., Pang R., Chen C., Chen Y., Zhang H.

Table 3. The statistics of the pore distribution of the MOS cement.

\begin{tabular}{lcccc}
\hline $\begin{array}{l}\text { Test } \\
\text { number }\end{array}$ & $\begin{array}{c}\text { Average pore } \\
\text { diameter }\end{array}$ & $\begin{array}{c}\leq 10 \mathrm{~nm} \\
(\%)\end{array}$ & $\begin{array}{c}10 \mathrm{~nm}-100 \mathrm{~nm} \\
(\%)\end{array}$ & $\begin{array}{c}\geq 100 \mathrm{~nm} \\
(\%)\end{array}$ \\
\hline Ca0K0 & 7 & 0 & 0 & 0.31 \\
Ca1K0 & 7 & 0.001 & 0 & 0.31 \\
Ca2K0 & 7 & 0.0015 & 0 & 0.31 \\
Ca3K0 & 7 & 0.002 & 0 & 0.31 \\
Ca0K1 & 7 & 0 & 0.002 & 0.31 \\
Ca0K2 & 7 & 0 & 0.003 & 0.31 \\
Ca0K3 & 7 & 0 & 0.004 & 0.31 \\
\hline
\end{tabular}

in a decrease in the average pore size. At the same time, since the product is a crystal, the pores are filled only for the macropores and mesopores, which is also the reason why the ratio of the $(D \geq 10 \mathrm{~nm})$ aperture is increased. Second, the ratio of the small pore size $(\mathrm{D}<10 \mathrm{~nm})$ of the sample after water soaking will increase, which may be due to the $\mathrm{MgO}-\mathrm{MgSO}_{4}-\mathrm{H}_{2} \mathrm{O}$ ternary gel hydration product in the test piece, and the dissolution of the gel increases the specific gravity of the small pore size.

\section{CONCLUSION}

In this study, the effects of different dihydrogen phosphates on the mechanical properties, hydration product composition, cement hydration heat release, porosity, and water resistance of MOS cement were investigated. The following conclusions were drawn:

- The readily soluble potassium dihydrogen phosphate and the insoluble calcium dihydrogen phosphate can be used as modifiers for MOS cement to improve the compressive strength of the MOS cement. This generally changes the phase of the product by the action of the admixture, promotes the growth of the $5 \cdot 1 \cdot 7$ phase in the MOS cement, and provides the main strength phase for the MOS cement.

- Calcium dihydrogen phosphate and potassium dihydrogen phosphate have a retarding effect, and the induction period becomes longer as the dosage increases, and the early strength is affected. However, the highest exotherm per unit time will decrease with the increase in the dihydrogen phosphate content, which is of great significance in the prevention of cracking of the concrete mass.

- As a modifier in MOS cement, dihydrogen phosphate not only changes the phase of the product but also changes the pore structure of the MOS cement. Since the $5 \cdot 1.7$ phase product has good water resistance, it improves the water resistance of the MOS cement.

Dihydrogen phosphate can be used as a modifier for MOS and does not affect the solubility in the magnesium sulfate solution. However, when two dihydrogen phosphates are used as modifiers, an effect of the MOS on the retardation is observed and brings disadvantages to the industrial production efficiency. In addition, it is necessary to further explore how to improve the initial strength of the MOS, shorten the clogging time of the MOS, and improve the efficiency in the industrial production, which will provide valuable insight into the industrial production of the MOS cement.

\section{Acknowledgment}

This study was supported by the National Natural Science Foundations of China (Grant no. 51662035) and the applied fundamental research project of Qinghai Province (Grant no. 2019-ZJ-7005) and the Science and Key $R \& D$ and transformation planned project of Qinghai province (Grant no. 2019-NN-159) and the S\&T Foundation Platform of Qinghai Province (Grant no. 2018-ZJ-T01) and the teaching team of the civil engineering safety technology of Qinghai University (Grant no. TD1804)

\section{REFERENCES}

1. Sam A., Walling, John L. P., (2016): Magnesium-based cements: a journey of 150 years, and cements for the future. Chemical Reviews, 116 (7), 4170-4204. doi: 10.1021/acs. chemrev.5b00463

2. Runčevski T., Wu C., Yu H., Yang B., Dinnebier R. E. (2013): Structural characterization of a new magnesium oxysulfate hydrate cement phase and its surface reactions with atmospheric carbon dioxide. Journal of the American Ceramic Society, 96(11), 3609-3616. doi: 10.1111/jace. 12556

3. Beaudion J.J., Ramachandran V.S. (1977): Strength development in magnesium oxysulfate cement. Cement and Concrete Research, 8(1), 103-112. doi: 10.1016/0008-8846 (78)90063-7.

4. Kahle K. (1972): Mechanism formation of magnesiumsulfate cements. Silikatechnik, 23 (5), 148-151.

5. Kishimoto T., Yamamoto S. (2009). Modified magnesium oxysulfate fibrous particles, useful e.g. in polyolefin composition, comprises magnesium oxysulfate fibrous particlestreated on their surfaces with necleating agent comprising. e. g. phosphoric acid compounds. Patent US2009292047-A1. 
6. Chengyou W., Wenhai C., Huifang Z., Wuyu Z., Ningshan J., Linxin L. (2017): The hydration mechanism and performance of Modified magnesium oxysulfe cement by tartaric acid. Construction and Building Materials, 144, 516-524. doi:10.1016/j.conbuildmat.2017.03.222

7. Chau C.K., Zongjin L. (2008):Microstructures of magnesium oxychloride. Materials and Structures, 41, 853-862. doi: 10.1617/s11527-007-9289-y

8. Urwong L., Sorrell C.A. (1980): Phase relations in magnesium oxysulfate cements. Journal of the American Ceramic Society, 63 (9-10),523-526. doi: 10.1111/j.1151-2916.1980. tb10757.x

9. Robert E., Dinnrbier, Melanie P., Daniela F. (2013): $3 \mathrm{Mg}(\mathrm{OH})_{2} \cdot \mathrm{MgSO}_{4} \cdot 8 \mathrm{H}_{2} \mathrm{O}:$ A Metastable Phase in the System $\mathrm{Mg}(\mathrm{OH})_{2}-\mathrm{MgSO}_{4}-\mathrm{H}_{2} \mathrm{O}$. Zeitschrift für Anorganische und Allgemeine Chemie, 639(10),1827-1833.

10. Chengyou W., HongfaY., Huifang Z., Jinmei D., Jing W., Yongshan T. (2015): Effects of phosphoric acid and phosphates on magnesium oxysulfate cement. Materials and Structures, 48(4), 907-917. Doi: 10.1617/s11527-0130202-6

11. Chengyou W., Huifang Z., HongfaY. (2016): Preparation and properties of modified magnesium oxysulfate cement derived from waste sulfuric acid. Advances in Cement Research, 28(3), 178-188. doi: 10.1680/jadcr.15.00011.

12. Chengyou W., HongfaY.,Jinmei D. , Lina Z. (2014): Effects of Material Ratio, Fly Ash, and Citric Acid on Magnesium Oxysulfate Cement. ACI Materials Journal, 111(3), 291-297. doi: 10.14359/51686723.

13. Zajac M., Skocek J., Bullerjahn F., Ben Haha M. (2016): Effect of retarders on the early hydration of calciumsulpho-aluminate (CSA) type cements. Cement and Concrete Research, 84(6), 62-75. doi: 10.1016/j.cemconres. 2016.02.014

14. Bishop M., Bott S.G., Barron A.R. (2003): A new mechanism for cement hydration: solid-state chemistry of calcium nitrilotris(methylene)triphosphonate. Chemistry of Materials, 15(16), 3074-3088. doi: 10.1021/cm0302431

15. Griffin J.L.W., Coveney P.V., Whiting A. (1999): Design and synthesis of macrocyclic ligands for interaction with crys- talline ettringite and demonstration of available mechanism for the setting of cement. Journal of the Chemical Society, Perkin Transactions, 2, 1973-1981. Doi: 10.1039/A902760B
16. Ramachandran V.S., Lowery M.S., Wise T., Polomark G.M. (1993): The role of phosphonates in the hydration of Portland cement. Matériaux et Construction, 26(161), 425-432. doi: 10.1007/BF02472943.

17. Billingham J., Francis D.T.I., King A.C et al. (2005): A multiphase model for the early stages of the hydration of retarded oilwell cement. Journal of Engineering Mathematics, 53(2), 99-112. doi: 10.1007/s10665-005-9003-4.

18. Black S.N., Bromley L.A., Cottier D. et al. (1991): Interactions at the organic inorganic interface-binding motifs for phosphonates at the surface of barite crystals. Journal of the Chemical Society, Faraday Transactions, 87(20), 3409-3414. Doi: 10.1039/FT9918703409

19. Rohl A.L., Gay D.H., Davey R.J., Catlow C.R.A. (1996): Interactions at the organic/inorganic interface: molecular modeling of the interaction between diphosphonates and the surfaces of baritecrystals. Journal of the American Chemical Society, 118(3), 642-648.doi: 10.1021/ja951443j

20. Wallner C.E. (2010). Cementitious veneer useful for forming laminated tiles/panels in building applications comprises magnesium oxysulfate compound comprising e.g. magnesium sulfate; and cementitious composition comprising e.g. hydrate calcium sulfate. USA patent US2010222457-A1; US8182605-B2

21. Deng D.H. (2003): The mechanism for soluble phosphates to improve the water resistance of magnesium oxychloride cement. Cement and Concrete Research, 33(9),1311-1317. doi: 10.1016/S0008-8846(03)00043-7

22. Jinmei D., Hongfa Y., Liming Z. (2010): Study on Experimental Conditions for Determination of Active $\mathrm{MgO}$ Content by Water Law. Journal of Salt Lake Research, 18(1), 38-41.

23. Jin W., Hongfa Y., Ying L., Chengyou W., Jinmei D. (2014): Effects of citric acid on hydration process and mechanical properties of thermal decomposed magnesium oxychloride cement. Journal of Wuhan University of Technology -Materials Science Edition, 29(1), 114-118. doi: 10.1007/s11595-014-0877-8

24. Jeffery J.T. (2007): A new approach to modeling the nucleation and growth kinetics of tricalcium silicate hydration. Journal of the American Ceramic Society, 90(10) 3282-3288. doi: 10.1111/j.1551-2916.2007.01858.x. 